\title{
VIVÊNCIA COM A NATUREZA NO AMBIENTE ESCOLAR NA PRIMEIRA INFÂNCIA E SUA RELEVÂNCIA PARA CONSTRUÇÃO DO RESPEITO E CUIDADOS COM O MEIO AMBIENTE
}

\author{
Graciele Cristiane Rambo ${ }^{1}$ \\ Marli Renate von Borstel Roesler ${ }^{2}$
}

Resumo: Dentre as fases do desenvolvimento humano, a primeira infância é considerada a mais sensível às influências que os meios social e físico podem exercer sobre esse desenvolvimento. $O$ que a criança vivencia durante essa etapa pode influenciar mais profundamente a construção da sua personalidade que qualquer outra idade. Sendo assim, considerando que cada vez mais cedo as crianças passam a frequentar os espaços escolares, e lá permanecem por longo período do dia confinadas em espaços fechados, evidências apontam que essa realidade tem colocado as crianças em situação de distanciamento da natureza, o que tem contribuído para a separação da criança em relação ao amor e aos cuidados com o meio ambiente. Nesse sentido, o presente artigo tem como objetivo discutir o papel indispensável que o espaço escolar assume: o de ressignificar a importância do meio ambiente no desenvolvimento infantil, e despertar o sentimento de pertencimento da criança à natureza, a começar pelo contato que ela pode e deve ter com os elementos do meio natural, no dia a dia escolar, contribuindo com isso para a formação de indivíduos reflexivos diante de atitudes positivas em relação ao meio ambiente, sempre em busca da promoção da sustentabilidade da vida.

Palavras-chave: Primeira Infância; Natureza; Sustentabilidade.

${ }^{1}$ Universidade Estadual do Oeste do Paraná - UNIOESTE. E-mail: graciele.rambo@hotmail.com 2Universidade Estadual do Oeste do Paraná - UNIOESTE. E-mail: marliroesler@hotmail.com 


\section{Introdução}

O presente artigo objetiva analisar a importância da primeira infância no processo de desenvolvimento do ser humano, e do seu direito ao contato e convívio com a natureza. Tem-se que é na educação básica (educação infantil), através do processo lúdico das brincadeiras em espaços livres, que estas podem contribuir para o despertar do amor e dos cuidados para com a mãe Terra, visando com isso a promoção da sustentabilidade almejada.

Assim, entendendo que durante essa fase do desenvolvimento infantil a criança passa a frequentar os espaços formais de ensino, faz-se necessário refletir como esses têm favorecido a promoção do contato com a natureza e o despertar dos cuidados com a Terra.

Considerando-se que a sustentabilidade não acontece mecanicamente, mas que ela é fruto de um processo contínuo de educação pela qual o ser humano redefine sua relação com a Terra, torna-se necessário refletir sobre o ensino e os espaços destinados à aprendizagem, ofertados nas escolas. Conforme aponta Boff, para reconhecer que a Terra é Mãe, a qual é um superorganismo vivo com recursos escassos, não se pode ensinar aos alunos apenas dentro das salas de aula, ou nos recintos fechados da biblioteca. Eles precisam ser levados a experimentarem na pele a natureza, a conhecerem a biodiversidade, bem como a história da paisagem que os cercam (BOFF, 2012, p. 153).

Para tanto, já não é cabível argumentar que se está sem tempo para refletirmos sobre a importância da educação voltada para um modo sustentável de se viver, e isto requer cuidados com a formação ambiental da criança, a fim de poder contribuir significativamente para a construção de um caminho de amor e cuidados com nosso bem comum: a Terra.

Considera-se que a escola, nesse contexto, torna-se espaço privilegiado ao se utilizar da formação ambiental para promover ações orientadas que levem a atitudes positivas, e ao comprometimento pessoal com relação à proteção ambiental. Desta forma, pode-se compreender o significado de sustentabilidade como um processo por meio do qual as crianças aprendem como funciona o ambiente, como dependemos dele, como o afetamos negativamente, e como é possível promover ações com vistas aos cuidados que o mesmo exige (DIAS, 2004). Seber, por sua vez, considera a importância da formação ambiental na primeira infância, tendo em vista que muitos valores são formados durante essa fase, pois "o conhecimento é construído durante as interações da criança com o mundo" (SEBER, 1989, p. 14). 


\section{Relação do ser humano com a natureza}

A natureza sempre foi algo a ser vencido e dominado pelo homem desde os tempos mais remotos da história da humanidade. Os primeiros indicativos de domínio através do desenvolvimento e do progresso surgem por volta do século XV.

Conforme aponta Carvalho, firmou-se um modelo de sociedade urbana e mercantil, em contraposição ao medieval camponês existente. Assim, conforme avança esse projeto civilizatório moderno, o passado medieval adquire sentido negativo, "sendo qualificado como inculto, menos desenvolvido, período das trevas". " $A$ ideia de civilidade e cultura era então construído como polo oposto à esfera associada à natureza, ao selvagem, à barbárie, à desrazão, à ignorância" e o conceito de civilização passa a ser associado ao progresso (CARVALHO, 2012, p. 95).

Nesse contexto, é demarcado o território humano civilizado contra a natureza selvagem, a natureza ameaçadora que precisa ser dominada para que aconteça o progresso da humanidade.

No entanto, foi o século XVIII que testemunhou uma das maiores formas de domínio humano sobre o ambiente, colocando a técnica a serviço do progresso e tornando possível a experiência da primeira Revolução Industrial que mudaria o mundo. O domínio da natureza pelas ciências e pelas tecnologias se transforma no projeto central das sociedades modernas. A técnica, antes um simples meio, passa a ser, como moderna tecnologia, a própria finalidade. No entanto, esse 'domínio' trouxe inúmeros resultados inesperados para a humanidade: a degradação ambiental e a desconstrução do mito de que os recursos naturais seriam ilimitados (ALENCASTRO, 2009, p. 17).

Alencastro corrobora dizendo que a atual crise ambiental que assola a humanidade é fruto das ações que têm caracterizado as modernas sociedades industriais capitalistas, que:

(...) veem o ambiente natural apenas como fonte de matériaprima para produção de mercadorias, e a natureza apenas como algo aberto e disponível para todo tipo de manipulação e exploração técnico-cientifica com fins econômicos (ALENCASTRO, 2009, p. 14).

$\mathrm{Na}$ visão de Gadotti, o capitalismo colocou os indivíduos em uma situação negativa com relação à natureza, através do potencial destrutivo gerado por esse sistema de produção de bens, resultado de um modelo de desenvolvimento social pautado no lucro e na exploração dos recursos naturais (GADOTTI, 2000, p.31).

Por outro lado, Boff complementa mencionando que uma das características da nossa civilização é o 'poder-dominação', o qual ganhou forma através da tecnologia. Para ele, somos indiscutivelmente uma civilização 
tecnológica, e usamos essa ferramenta para nos relacionarmos com a natureza, para nosso propósito de poder-dominação, ou seja, "ao interesse do poder, desconsiderando o valor intrínseco dos seres da natureza e fazendo-os logo meio (instrumento) para fins da subjetividade humana, normalmente de lucro e de bem-estar individual" (BOFF, 1995, p. 115).

Boff, dentro do contexto de visão antropocêntrica, considera os seres humanos dissociados da natureza e dela serem dominadores, aumentando a distância do homem e seu cuidado com a Terra que, por sua vez, tem sofrido a ameaça do predador humano. Segundo o texto abaixo:

(...) no século XVIII, a população mundial cresceu 8 vezes, consumindo mais e mais recursos naturais, somente a produção, baseada na exploração da natureza, cresceu mais de cem vezes. O agravamento deste quadro com a mundialização do acelerado processo produtivo faz aumentar a ameaça e, consequentemente, a necessidade de um cuidado especial com o futuro da Terra (BOFF, 2001, p. 133).

É chegada a hora de rever a situação, bem como a relação do homem com o meio natural, para evitar a destruição da Terra de forma talvez definitiva.

Conforme destaca Carvalho, diante da situação de degradação ambiental vivenciada, a Educação Ambiental tem a oportunidade de problematizar os diferentes interesses e forças sociais que se estabelecem em torno das questões ambientais. E como prática educativa e reflexiva, possibilita a observação e a compreensão no fortalecimento de uma ética que articula a sensibilidade ecológica, voltada para a construção de uma cidadania ambientalmente sustentável (CARVALHO, 2012, p. 106).

A educação, nesse contexto, entra como uma grande aliada na desconstrução do conceito de 'senhores do universo', o qual tem atribuído aos seres humanos o destino do planeta Terra, podendo a educação contribuir para a construção de sujeitos mais cientes e atuantes na preservação da natureza.

Mas, para isso, é importante que a escola contribua para ressignificar a importância do meio ambiente, começando pelo contato que ela pode proporcionar ao aluno com os elementos da natureza no dia a dia de suas práticas pedagógicas, como forma de reaproximar os sujeitos do mundo natural, e resgatar a intimidade perdida ao longo de séculos de distanciamento, atuando em especial na primeira infância, fase essa do desenvolvimento humano em que diversos aspectos, como o cognitivo, motor, social e emocional, estão sendo formados e construídos.

\section{Marco da Primeira Infância e o desenvolvimento infantil}

O cuidado com a criança tem sido tema de debates ao longo dos anos, desenvolvimento dentro da sociedade, e assim garantir uma infância plena no 
que se refere aos cuidados ambientais e, por conseguinte, à educação ambiental.

Dentre essas ações, podemos citar o Estatuto da Criança e do Adolescente - ECA, o qual dispõe sobre a proteção integral da criança e do adolescente, bem como, sobre o dever da família, da sociedade em geral, e do poder público, para assegurar a efetivação dos direitos e deveres da criança (BRASIL, 1990). O mesmo faz a Lei de Diretrizes e Bases da Educação Nacional - LDB, que trata da educação escolar realizada em instituições próprias, trazendo em seus princípios, o direito à educação, dentre outros (BRASIL, 2006).

Ambas as cartas têm como referência a categorização de crianças, conforme previsto no art. $2^{\circ}$, do Estatuto da Criança e do Adolescente - ECA, segundo o qual "considera-se criança a pessoa de até doze anos de idade" (BRASIL, 1990).

Apesar do ECA considerar criança a pessoa até doze anos de idade, entende-se que o ser humano, desde seu nascimento até a fase adulta, passa por processo de desenvolvimento contínuo, e que este, nos primeiros anos de vida, não tem as mesmas características, fragilidades e construções de aprendizagem, que outra fase próxima do fim do estabelecido como 'criança' possa ter (BRASIL, 1990).

Por outro lado, reconhecendo essa diferença dentro do processo de desenvolvimento, a Lei 13.257 de 09 de março de 2016, dispõe sobre as Políticas Públicas para a Primeira Infância, e estabelece no Art. 2º, que "primeira infância é o período que abrange os primeiros 6 (seis) anos completos ou 72 (setenta e dois) meses de vida da criança" (BRASIL, 2016).

Essa delimitação considera a Primeira Infância como o período da vida humana mais sensível às influências do meio social e físico. O que a criança vive, sente, vê, experimenta, marca mais profundamente sua personalidade do que em qualquer outra idade. Se ela é mais suscetível de ser influenciada pelo meio, é também nessa fase que seu potencial está mais propenso para as aprendizagens básicas (DIDONET, 2018).

A área que muito contribuiu para esse entendimento foi a Psicologia Interacionista, embasada no entendimento de que o desenvolvimento do ser humano, e sua aprendizagem, é um processo puramente exterior, e apoia-se na interação que se estabelece entre o organismo e o meio, isso consoante a visão de Carvalho:

De um modo geral, pode-se dizer que o interacionismo simbólico constitui uma perspectiva teórica que possibilita a compreensão do modo como os indivíduos interpretam os objetos e as outras pessoas com as quais interagem e como tal processo de interpretação conduz o comportamento individual em situações específicas (CARVALHO et al., 2010, p. 148). 
Dentre os grandes nomes de pensadores interacionistas, que contribuíram significativamente para a educação voltada ao desenvolvimento da aprendizagem, podemos mencionar Lev Vygotsky ${ }^{3}$ e Jean Piaget ${ }^{4}$.

Apesar de suas obras apresentarem, em alguns momentos, pontos distintos, ao mesmo tempo se completam quanto à forma de ver o ser humano, e sua forma de interagir com o meio no qual se encontra.

Para Vygotsky, o desenvolvimento humano e as relações entre desenvolvimento e aprendizado, são temas centrais de seus trabalhos, apesar de não delimitar as fases do desenvolvimento por idade ou etapas, pois, para ele, aprendizagem e desenvolvimento se relacionam durante toda a vida, considerando que o sujeito, ao aprender, promove seu desenvolvimento, e ao desenvolver-se, gera novas aprendizagens (MOLON, 2009, p.159).

Sendo assim, em seus estudos, trabalhou com o conceito de desenvolvimento proximal, ou seja:

(...) é a distância entre o nível de desenvolvimento real, que se costuma determinar através da solução independente de problemas, e o nível de desenvolvimento potencial, determinado através da solução de problemas sob a orientação de um adulto ou em colaboração com companheiros mais capazes" (VYGOTSKY, 1991, p. 58).

Assim, essa 'zona de desenvolvimento proximal' descrita pelo autor, nada mais representa do que as funções que ainda não amadureceram, mas que estão em processo de maturação, sendo essa a capacidade que a criança tem de aprender mediante a interação com o meio através dos níveis de amadurecimento já construídos, como ele pontua:

Aquilo que é a zona de desenvolvimento proximal hoje, será o nível de desenvolvimento real amanhã - ou seja, aquilo que uma criança pode fazer com assistência hoje, ela será capaz de fazer sozinha amanhã" (VYGOTSKY, 1991, p. 58).

${ }^{3}$ Lev Semenovich Vygotsky (1896 - 1934) nasceu em Orsha na Rússia. De família judaica culta e de boas condições financeiras, o que possibilitou uma formação sólida desde a infância. Formou-se em direito, lecionou literatura, estética e história da arte. Fundou um laboratório de psicologia - área que logo ganhou destaque graças ao seu vasto conhecimento. Publicou mais de 200 trabalhos científicos. Sua obra ressalta o papel da escola no desenvolvimento psicológico da criança, sendo uma das mais estudadas pela pedagogia contemporânea (REVISTA NOVA ESCOLA, 2006, p.58)

4 Jean Piaget (1896 - 1980) nasceu em Neuchâtel na Suíça. Formou-se em biologia e começou a trabalhar com o estudo do raciocínio da criança sob a ótica experimental, escrevendo mais de 50 livros. Seus estudos sobre o desenvolvimento da inteligência humana revolucionaram a forma de encarar a educação da criança ao mostrar que elas não pensam como adultos, mas constroem o próprio pensamento (REVISTA NOVA ESCOLA, 2006, p.55).

Revbea, São Paulo, V. 14, № 1: 111-131, 2019. 
Sob esse aspecto, o papel dos educadores torna-se fundamental na mediação do conhecimento que será proporcionado ao aluno, pois são eles "os responsáveis pela organização do contexto pedagógico e do meio social e pela socialização e apropriação dos diferentes tipos e conhecimento produzidos histórica e socialmente", permitindo com isso ultrapassar os limites estabelecidos pelas disciplinas, visando a formação integral e reflexiva ao confrontar os conteúdos curriculares com a realidade de mundo observado pelo aluno (MOLON, 2009, p.162).

Por outro lado, para Piaget, a primeira relação do ser com o meio é chamada de adaptação, com seus dois aspectos complementares: a assimilação e a acomodação. E Flavell, embasado em Piaget, atesta que:

A adaptação se dá sempre que um determinado intercâmbio organismo-ambiente tem como efeito modificador do organismo de modo que os intercâmbios posteriores, favoráveis à sua conservação, são intensificados (PIAGET, 1952, p.2 apud FLAVELL, 1996, p.45).

A adaptação nada mais é do que o equilíbrio que a criança estabelece com o meio em que vive, isso através do processo pelo qual os elementos do exterior são internalizados à sua estrutura de pensamento. Dessa forma, a assimilação acontece quando a criança modifica suas estruturas cognitivas em formação, para melhor incorporar-se ao objeto ou ao fato externo, ocorrendo assim a aprendizagem consoante (FERRACIOLI, 1999).

Outra pesquisadora que contribuiu para melhor compressão da infância foi Maria Montessori ${ }^{5}$, demostrando que a criança tem mundo próprio e tem o direito de vivê-lo. Seu primeiro ensinamento refletia sobre a importância de o adulto aprender mais sobre o mundo da criança, sem lhe impor seu modo de pensar. O segundo ensinamento levou ao mundo a compressão mais abrangente, demonstrando que as crianças aprendem melhor quando envoltas por uma "atmosfera feliz, onde Ihe seja ofertada a liberdade de controlar suas próprias atividades" (POLLARD, 1990, p. 58).

A autora, em seus estudos, trabalhou a influência do meio ambiente para o desenvolvimento da criança, e isso tornou-se o centro de toda a sua

\footnotetext{
5 Criadora do Método Montessori, nasceu em 1870 em Chiaravalle, norte da Itália. Desde pequena se interessou pela ciência. Contrariando os anseios de seus pais, tornou-se a primeira médica mulher da Itália. Seus estudos se voltaram para a psiquiatria. Primeiramente trabalhou com crianças com retardos mentais, consideradas ineducáveis, e percebeu que elas poderiam ser estimuladas noutro sentido. Suas experiências e observações a levaram ao trabalho com crianças tidas como 'normais'. Em 1907, criou a primeira "Casa dei Bambini", ou "Casa das Crianças". Esse espaço foi projetado com mobílias baixas o suficiente para ser segura para as crianças, e com isso permitir que estas adquirissem autonomia na aprendizagem. Seus estudos visavam observar as crianças e os motivos de suas ações (RÖHRS, 2010).
}

revista brasileira educação ambiental 
construção pedagógica, abordando aspectos relacionados à existência da sensibilidade interna da criança, ao apontar que:

Há um período sensível muito prolongado, quase até aos cinco anos, que torna a criança prodigiosamente capaz de se apropriar das imagens do ambiente, e por conseguinte, a transforma num observador que capta ativamente as imagens por intermédio dos sentidos (MONTESSORI, 1980?, p. 64).

Em seus escritos sobre a sensibilidade da criança, a autora chama atenção para uma em específico: "o amor ao ambiente". Essa ação possibilita "à criança observar as coisas com paixão e é por elas atraída, mas, sobretudo é atraída pelos atos do adulto para conhecer e reproduzir" (MONTESSORI, 1980?, p.91).

Nesse aspecto, cabe destacar que a criança, em sua essência, é atraída naturalmente para o mundo da descoberta através do ambiente que lhe é oportunizado, no qual, dentro de seu ritmo individual, observa, reflete, constrói hipóteses e experimenta. No entanto, esse processo por vezes é interrompido pelo ritmo acelerado sugestionado pelo adulto, tendo em vista que "a sociedade, insensível a qualquer forma de responsabilidade, abandona a criança aos cuidados da família, e esta por sua vez entrega-a à sociedade que a fecha numa escola", e com isso nasce o drama social da criança (MONTESSORI, 1980, p.203).

O drama social da criança, e referido pela autora, diz respeito ao espaço escolar ao qual a criança é levada desde muito pequena. Um lugar construído por adultos e para adultos, e não para pessoas ainda em crescimento. Espaço esse com portas, janelas, corredores, mobília, e duração das aulas na proporção, na visão e no desejo do adulto. É nesse ambiente pensado por adultos, que a criança permanecerá por longos anos da sua vida. Todos os dias ela entrará em uma sala de aula, a porta se fechará, e o mundo exterior que tanto move a sua curiosidade, por vezes será apenas narrado em meio a quatro paredes, tornando esse lugar, conforme Montessori denominou, uma 'cidade habitada por gente perdida'

Dentro dos apontamentos apresentados quanto ao desenvolvimento infantil, percebe-se a importância da vivência da criança com o ambiente, e consequentemente com a natureza durante a sua Primeira Infância, isso como forma de conhecê-la, de entender sua importância e, acima de tudo, sentir-se parte dela. O professor, nesse contexto, torna-se peça chave quanto às oportunidades que pode ofertar à criança ao colocá-la em contato com seu meio natural através de espaços abertos para que, a partir de então, possa construir as bases de aprendizagem marcadas pelos cuidados e preservação desse meio. 


\section{A importância do brincar no desenvolvimento da criança}

Uma atividade muito característica durante a fase da infância é o ato de brincar. A questão do brincar tem sido alvo de inúmeras pesquisas, principalmente pela psicologia, devido à influência que exerce no desenvolvimento infantil. Essa particularidade se dá somente nessa fase do desenvolvimento humano, e pode contribuir ao trazer inúmeras vantagens através da experiência para o desenvolvimento futuro da criança.

Assim o brinquedo, ou $\mathrm{o}$ ato de brincar, proporciona à criança a oportunidade da construção de um mundo imaginário de faz-de-conta, onde, aos poucos, ela se apropria das regras do convívio coletivo e social, conforme ensina Vygotsky:

Apesar da relação brinquedo-desenvolvimento poder ser comparada à relação instrução desenvolvimento, o brinquedo fornece ampla estrutura básica para mudanças das necessidades e da consciência. A ação na esfera imaginativa, numa situação imaginária, a criação das intenções voluntárias e a formação dos planos da vida real e motivações volitivas tudo aparece no brinquedo, que se constitui, assim, no mais alto nível de desenvolvimento pré-escolar. A criança desenvolve-se, essencialmente, através da atividade de brinquedo (VYGOTSKY, 1991, p. 69).

Portanto, a escola ao proporcionar espaços abertos, ao ar livre, em contato com a natureza para a criança brincar, pode contribuir para a construção de regras, de valores, e cuidados que poderão acompanhá-la durante todo seu desenvolvimento. Nesse sentido, conforme aponta Piorski, ao brincar de fazer de conta, a criança assume na sua fala, no seu pensar, e no imaginar, as estruturas simbólicas que mais tarde a ajudarão a interagir, interpretar e dar significado para as coisas, que despontarão no nascimento da sua consciência (PIORSKI, 2016, p.27).

A escola, enquanto instituição formadora, torna-se ambiente no qual experiências importantes da infância serão vividas. Restringir aos discentes 0 emparedamento de uma sala de aula, é nega-Ihes o direito à brincadeira previsto no Estatuto da Criança e do Adolescente que, em seu Art. 16으, estabelece "o direito à liberdade compreende os seguintes aspectos: IV brincar, praticar esportes e divertir-se" (BRASIL, 1990).

O brincar, conforme visto, além de ser considerado um direito na infância, possibilita que a aprendizagem seja ressignificada e amadurecida, na medida em que o ambiente de aprendizagem ofereça novos desafios.

Dessa forma, Barros destaca que permitir que a criança brinque com material advindo da natureza atende à sua vontade de construir, criar e montar. Fato esse que possibilita o desenvolvimento de habilidades motoras e de criação cada vez mais complexas na relação com o mundo à sua volta.

revista brasileira educação ambiental 
Nessa perspectiva, Barros sugere que sejam ofertados às crianças alguns materiais como ferramentas lúdicas, tais como: 1) Brinquedos de madeira: os quais possuem peso, textura, durabilidade, e aroma diferente dos brinquedos industrializados; 2) Utensílios de cozinha de louça, madeira ou metal: que acionam a imitação do mundo real, o do adulto; 3) Materiais não estruturados: restos de madeiras, cascas, sementes, pedras, palha, conchas, etc, os quais favorecem o potencial criativo das crianças, cujas partes soltas proporcionam a autoria do fazer e do aprender; 4) Elementos naturais: terra, areia, ar, água, barro e fogo. Cada um deles traz mensagem especial e uma sensação diferente para a criança. Isso permite vencer o medo que os adultos têm de que a criança adoeça, o que a afasta, por exemplo, do contato com a água (BARROS, 2018, p. 77-78).

Nesse sentido, a proximidade com diferentes elementos contribui para que a criança forme suas próprias ideias e hipóteses sobre a formação do mundo, bem como dos elementos naturais que compõem a vida humana.

Dessa forma, o brincar em espaços livres na Primeira Infância, apresenta aspecto muito importante dentro do contexto de desenvolvimento da mesma, pois durante esses momentos ela cria situações de faz de conta, o que motiva a sua criatividade dentro de um mundo imaginário no qual se utiliza de objetos da sua própria realidade para formar seu cenário, fazendo assim a ligação entre a realidade e a imaginação.

Essas vivências contribuem para seu pleno desenvolvimento, e com isso adquire conhecimento, supera limitações e desenvolve-se como indivíduo, segundo considerações que Santos faz a respeito:

O lúdico pode ser caracterizado como sendo um momento prazeroso de interação e aprendizagem, contribuindo assim, de maneira significativa no que diz respeito ao processo de socialização, expressão, construção do pensamento e comunicação (SANTOS, 2011, p. 12).

Assim, podemos considerar que o ato de brincar pode proporcionar à criança uma aprendizagem significativa, pois permite que ela se relacione com o mundo que a cerca como algo prazeroso.

Dessa forma, é preciso considerar os espaços externos da escola nos quais ocorrerá os momentos livres para brincadeiras e socialização do conhecimento, como uma extensão da sala de aula, pois não só ela é espaço de aprendizagem. Nesse conceito, todo lugar em que a criança possa trocar experiências e se sentir viva, disposta, e motivada a aprender, pode ser visto como espaço de aprendizagem, principalmente se nesse espaço se possibilitar à criança o contato com elementos da natureza.

Conforme aponta Barros, por meio do brincar livre através do convívio com a natureza, possibilitará o desenvolvimento da criatividade, da iniciativa, da autoconfiança, da capacidade de escolhas, de tomar decisões e resolver problemas, o que por sua vez contribui para o desenvolvimento integral da Revbea, São Paulo, V. 14, № 1: 111-131, 2019. 
criança. "Isso sem falar nos benefícios mais ligados aos campos da ética e da sensibilidade, como encantamento, empatia, humildade e senso de pertencimento", que o ambiente natural proporciona (BARROS, 2018, p.17).

Sendo assim, mais uma vez ressalta-se a importância do brincar para o desenvolvimento pleno da criança, e a importância do espaço que será proporcionado para esse momento lúdico, bem como, a ação pedagógica que será desenvolvida. O espaço ao qual aqui nos referimos, diz respeito ao que será ofertado dentro dos espaços formais de ensino, ou seja, o espaço ao 'ar livre' dentro da própria instituição, o qual possa colocar a criança o mais próximo possível dos elementos que compõem a natureza como: terra, pedra, água, areia, plantas, sementes e folhas.

\section{A vivência com a natureza na primeira infância}

A Educação Infantil, conforme aponta a Lei de Diretrizes e Bases da Educação Nacional - LDB em seu Art. 29 “(...) representa a primeira etapa da educação básica e tem como finalidade o desenvolvimento integral da criança de até 5 (cinco) anos (...)" (BRASIL, 1996).

$\mathrm{O}$ ato de considerar que toda criança tem direito a um ambiente saudável e ecologicamente equilibrado, respaldado no art. 225 da Constituição Federal (BRASIL, 1988), tem despertado o desejo de entender e analisar como as políticas públicas voltadas para esse espaço visam a garantir o convívio dela com a natureza, bem como, refletir sobre a importância que esse contato representa para o desenvolvimento integral da mesma, no que diz respeito à formação de cidadãos conscientes de seu papel perante o meio ambiente.

Ao levar-se em conta que somos seres biológicos e fazemos parte da natureza que nos cerca, e como tal, necessitamos com urgência desconstruir a relação antropocêntrica criada com a natureza, ou seja, onde o ser humano tem se colocado como se estivesse acima dela, ou dela não fizesse parte, delegando à natureza a função de lhe servir, desconsiderando que os recursos naturais são esgotáveis, consoante Tiriba, que esclarece:

A escola ensina às crianças um sentimento de si como membros de uma espécie superior, atribuindo-Ihes poderes de vida e morte sobre as demais: é a proprietária do mundo natural, que aos humanos deve se submeter, é a 'administradora' o planeta (TIRIBA, 2005, p.63).

No âmbito desse pensamento, é interessante destacar que no Brasil, o Observatório do PNE (Plano Nacional de Educação), em pesquisa realizada em 2015, revelou que $30,5 \%$ das crianças de 0 a 3 anos frequentavam a educação infantil. No entanto, o número sobe consideravelmente para 90,5\% quando se refere a crianças de 4 a 5 anos. E segundo o (PNE 2015), dentre essas, muitas frequentam em tempo integral o espaço formal de ensino sob a supervisão e orientação de um profissional que passa boa parte do dia com 
essas crianças. Considerando-se que uma criança, ao frequentar a educação infantil, pode lá permanecer de 04 a 12 horas diariamente, e nesse espaço de tempo ocorrem apenas alguns momentos de atividades livres fora da sala de aula, sendo essas atividades muitas vezes realizadas em espaços cobertos, e com piso cimentado.

Tal realidade desconsidera o mencionado nas Diretrizes Curriculares para a Educação Infantil, que orienta em seu Art. 9, que, dentro das práticas pedagógicas, sejam criadas situações, entre as quais: "VIII - incentivem a curiosidade, a exploração, o encantamento, o questionamento, a indagação e o conhecimento das crianças em relação ao mundo físico e social, ao tempo e à natureza”, bem como, “ $X$ - promovam a interação, o cuidado, a preservação e o conhecimento da biodiversidade e da sustentabilidade da vida na Terra, assim como o não desperdício dos recursos naturais" (BRASIL 2009).

Para tanto, cabe ao profissional da educação a missão de promover situações de contato dos pequenos com essa biodiversidade que os cerca. A qual, para ter sentido para a criança durante a Primeira Infância, precisa ser vivenciada na prática, fora da sala de aula, pois dentro da sala tudo que se pode trabalhar são aspectos abstratos, figurativos, e pouco atrativos para essa fase da vida. As Diretrizes Curriculares Nacionais para a Educação Ambiental apresentam as seguintes orientações:

Art. 17. Considerando os saberes e os valores da sustentabilidade, a diversidade de manifestações da vida, os princípios e os objetivos estabelecidos, o planejamento curricular e a gestão da instituição de ensino devem:

I - estimular:(..) d) vivências que promovam 0 reconhecimento, o respeito, a responsabilidade e o convívio cuidadoso com os seres vivos e seu habitat;

II - contribuir para: (...) d) a promoção do cuidado e responsabilidade com as diversas formas de vida, do respeito às pessoas, culturas e comunidades;

III - promover: observação e estudo da natureza e de seus sistemas de funcionamento para possibilitar a descoberta de como as formas de vida relacionam-se entre si e os ciclos naturais interligam-se e integram-se uns aos outros;

(...) c) projetos e atividades, inclusive artísticas e lúdicas, que valorizem o sentido de pertencimento dos seres humanos à natureza, a diversidade dos seres vivos, as diferentes culturas locais, a tradição oral, entre outras, inclusive desenvolvidas em espaços nos quais os estudantes se identifiquem como integrantes da natureza, estimulando a percepção do meio ambiente como fundamental para o exercício da cidadania (BRASIL, 2012, p.6 grifos nossos). 
Ao levar-se em conta as Diretrizes Curriculares que apontam o caminho para a importância da promoção do contato com a natureza, e analisando os apontamentos realçados por Tiriba (2004), que destaca em seu trabalho a importância das brincadeiras ao ar livre e o contato com os elementos do mundo natural, quais sejam: água, areia, terra, pedrinhas e plantas, etc; experiências essas cada vez mais raras, não estaria aí sendo construído o início do distanciamento da criança em relação à natureza e, por consequência, a degradação das condições da vida na terra? (TIRIBA et al., 2004).

Deve-se ressaltar que, nesse contexto, a Política Nacional de Educação Ambiental, em seu art. $2^{\circ}$, dispõe que "a educação ambiental é um componente essencial e permanente da educação nacional, devendo estar presente, de forma articulada, em todos os níveis e modalidades do processo educativo, em caráter formal e não-formal' (BRASIL, 1999). Isso adquire um aspecto emergencial visando uma outra forma de educar; um educar que reconecte a criança para valorizar o reconhecimento da vida e a importância do mundo que a cerca, e assim contribuir para a garantia do "direito ao meio ambiente ecologicamente equilibrado" (BRASIL, 1988).

A pedagogia, dentro desses aspectos abordados, precisa responder a essa necessidade emergente, entendendo que a atuação do professor, no dia a dia, pode afetar as condições de existência da sociedade como um todo, tal como afirmado por Leff ao dizer que "isto implica em educar para formar um pensamento crítico, criativo e prospectivo, capaz de analisar as complexas relações entre os processos naturais e sociais, para atuar no ambiente em uma perspectiva global (...)"(LEFF, 2015, p. 256).

Dessa forma, torna-se indispensável orientar a educação, dentro do contexto social e ecológico onde estão os sujeitos do processo educativo, através de experiências concretas com o meio físico e social, e buscar, a partir dali, soluções para os problemas ambientais.

Ao analisar a importância de trazer a natureza para o espaço escolar, Tiriba faz um interessante comentário relacionado ao espaço e modo de funcionamento das creches e pré-escolas, locais esses onde se verifica desrespeito com o desejo do corpo de estar ao ar livre, ao se colocar a criança em verdadeira situação de emparedamento. Isso torna-se ainda mais grave conforme os anos escolares aumentam. Segundo a autora, a criança, ao frequentar desde muito pequena as creches e escolas, acaba involuntariamente anulando os aspectos biológicos e sua natureza, e consequentemente acontece o afastamento entre o corpo e a mente, pois isso distancia de forma radical a criança do mundo da brincadeira ao ar livre, estabelecendo impasse entre o desejo, a natureza da criança, e as normas impostas pelos estabelecimentos de ensino através de rotinas pré estabelecidas (TIRIBA, 2008).

E Gadotti, afirma que muitos dos problemas ecológicos que presenciamos estão integralmente relacionados à nossa forma de viver, a qual 
é inculcada pela própria escola através do que ela seleciona como importante para o ensino, pois "na era do conhecimento, a pedagogia tornou-se a ciência mais importante porque ela objetiva justamente promover a aprendizagem. A era do conhecimento é também a era da sociedade 'aprendente' onde e quando todos tornam-se aprendizes", afirma o autor (GADOTTI, 2000, p. 45).

Nessa outra realidade proposta, o aluno deverá ser motivado a observar e pensar para aprender e, sobretudo, para desenvolver curiosidade em relação ao mundo à sua volta. Consequentemente, a pedagogia não estará mais centrada na didática de como ensinar, mas sim, em como se deve ensinar para despertar na criança outro saber, conforme segue:

A ecopedagogia pretende desenvolver um novo olhar sobre a educação, um olhar global, uma nova maneira de ser e de estar no mundo, um jeito de pensar a partir da vida cotidiana, que busca sentido a cada momento, em cada ato, que pensa a prática - Paulo Freire, em cada instante de nossas vidas, evitando a burocratização do olhar e do comportamento (GADOTTI, 1999, p. 82).

Quando abordamos a visão da Ecopedagogia, é importante perceber que ela e a Educação Ambiental andam muito próximas, tendo em vista que aquela, a Pedagogia da Terra ${ }^{6}$, tem uma visão holística, não sendo apenas para os educadores e educandos, mas para todos os habitantes do planeta tendo como "objetivo proporcionar discussões, reflexões e orientar a aprendizagem a partir da vivência cotidiana, subsidiada na percepção e no sentido das coisas", tornando-a tão significativa para o aprendiz a ponto de mudar seu comportamento, e proporcionar sua interação com o meio em que esteja inserido, buscando com isso a harmonia e a sustentabilidade (PEREIRA et al., 2007, p. 86).

Assim sendo, o espaço da educação infantil a ser vivenciado diariamente pelas crianças, por um número considerável de horas, acabará por ser tornar local privilegiado para o favorecimento de práticas pedagógicas significativas que visem o contato e, por conseguinte, conhecimento em relação à biodiversidade que cerca as crianças. Com essa outra prática pedagógica, agrega-se ainda qualidade de vida social e ambiental, para que elas cresçam reconhecendo a importância de cuidar e preservar a natureza de forma concreta e prática, e não apenas por algo baseado em imagens abstratas e de pouco significado para ela, retratados em fotos, vídeos e desenhos.

${ }^{6}$ Forma como também é conhecida a Ecopedagogia. O Precursor deste estudo é Cruz Prado e Francisco Guitiperrez, quando lançam em 1998 o livro intitulado "Ecopedagogia e cidadania planetária", no qual fazem um aprofundamento teórico no tocante a uma cidadania planetária que vai além da cidadania ambiental. Para eles, a ecopedagogia seria aquela que promove a aprendizagem do "sentido das coisas a partir da vida cotidiana" (PADILHA et al., 2011, p. 30).

Revbea, São Paulo, V. 14, № 1: 111-131, 2019. 
Dentro desse outro contexto pedagógico, cabe ao professor proporcionar atividades ao ar livre que possam reconectar a criança à natureza, aproximando-a da relação de pertencimento enquanto ser vivo deste planeta, para então estabelecer relação de amor e cuidados com sua própria existência, como bem nos ensina Tiriba (TIRIBA, et al. 2004).

Conforme aponta Ahlert "não se cuida o que não se conhece. Não se preserva se não se conhecem os sentidos da preservação". Em seu artigo, o autor traz reflexão sobre a ética voltada ao uso sustentável da água, haja vista podermos tomá-lo como referência para o trabalho que se inicia ainda na infância, no que diz respeito ao cuidar e preservar valores quando ensinados logo nos primeiros anos da infância. Ações essas que contribuem para o crescimento de indivíduos mais responsáveis e sensíveis diante da preservação ambiental, pois, conforme seus apontamentos, é preciso 'conhecer' para dar sentido ao que é necessário cuidar, ou seja, a criança precisa e deve ter contato com os elementos da natureza para que estes façam parte de sua vida (AHLERT, 2013, p. 1572).

\section{Sustentabilidade e educação}

Quando se propõe discutir cuidados em relação ao meio ambiente e ao planeta Terra, é impossível não falar de sustentabilidade ou desenvolvimento sustentável. Porém, apesar de parecer sinônimos, ao problematizarmos suas definições, compreenderemos 0 quanto esses conceitos se distanciam em suas finalidades. Para Loureiro, o conceito de sustentabilidade é oriundo "das ciências biológicas e se refere à capacidade de suporte de um ecossistema, permitindo sua reprodução ou permanecia no tempo". Por outro lado, a sustentabilidade é vista tanto no sentido material na produção e reprodução, quanto no sentido simbólico, como afeto, participação, identidade e liberdade (LOUREIRO, 2012, p. 56).

Aspectos esses que se tornam um tanto quanto desafiadores de serem almejados em uma sociedade na qual os interesses econômicos ainda demonstram estarem acima de tudo e de todos. Porém, para o referido autor, o conceito de desenvolvimento sustentável apresenta uma conotação de crescimento visto do ponto de vista da economia, pois "a este conceito vem acoplado o de evolução, que implicaria na noção de avanço constante, por meio da razão, do conhecimento científico", atrelados ao modelo de sociedade civilizada a ser alcançado, tornando-se sinônimo de crescimento econômico, do ponto de vista capitalista (LOUREIRO, 2012, p. 58).

Dentre as definições apresentadas, cabe destacar que o conceito aqui utilizado é a sustentabilidade, a qual visa ser incorporada e assumida pela educação, esta considerada muitas vezes como o único caminho para a conscientização ambiental dos sujeitos, sendo assim, responsável por grande parte das transformações sociais pretendidas.

Definidos os conceitos, podemos iniciar a discussão destacando que o modo de vida no planeta Terra, a forma de exploração dos seus recursos, o

revista brasileira educação ambiental 
desamor para com tudo que compõe esse imenso organismo vivo, tem, nas últimas décadas, causado considerável mal estar em relação ao descuido, ao descaso e abandono, quando se trata das causas naturais. Na visão de Boff, estamos vivendo uma 'crise civilizacional', que vivemos em decorrência do mundo prioritariamente capitalista, este regido pelo 'ter' muito mais do que o 'ser', mundo esse que não mede esforços na sanha de lucrar com a exploração das riquezas naturais cada vez mais escassas, e isso está relacionado apenas a duas palavras: 'falta de cuidado' (BOFF, 1999, p.18).

Essa falta de atenção, de cuidado, tem gerado descaso em relação ao meio ambiente, descaso esse que poderá levar o planeta ao caos iminente, o qual atingirá a todos os habitantes do planeta Terra, independentemente de classe social, como bem descreve o autor:

Há um descuido e um descaso na salvaguarda de nossa casa comum, o planeta Terra. Solos são envenenados, ares são contaminados, águas são poluídas, florestas são dizimadas, espécies de seres vivos são exterminadas; um manto de injustiça e de violência pesa sobre dois terços da humanidade. Um princípio de autodestruição está em ação, capaz de liquidar o sutil equilíbrio físico-químico e ecológico do planeta e devastar a biosfera, pondo assim em risco a continuidade do experimento da espécie homo sapiens e demens (BOFF, 1999, p. 20).

Essa crise, já mencionada por Boff, causada pela falta de cuidado com a Terra, é também discutida por Enrique Leff, mas do ponto de vista da racionalidade ambiental, ou seja:

A crise ambiental irrompeu no mundo nos últimos 40 anos como uma crítica à degradação ambiental gerada pelo crescimento econômico - e de forma mais generalizada pela racionalidade moderna - abrindo no campo da prospectiva social o imperativo da construção de um futuro sustentável (LEFF, 2010, p. 19).

Leff vai além, quando, em seus escritos, traz um discurso voltado à racionalidade ambiental que implica por sua vez em mudança de racionalidade social que inclui outras dimensões, e não se restringe apenas à esfera produtiva, pois não basta apenas questionar os impactos da economia e tecnologia na natureza e na cultura, ou defender a diversidade biológica e cultural. A sustentabilidade, para ele, implica em mudança de racionalidade social e produtiva (LEFF, 2010, p. 51).

Já Leonardo Boff acredita que, para chegarmos à verdadeira sustentabilidade, é preciso primeiramente falar de sociedade sustentável, ou seja:

Revbea, São Paulo, V. 14, № 1: 111-131, 2019. 
Sustentável é a sociedade ou planeta que produz o suficiente para si e para os seres dos ecossistemas onde ela se situa; que toma da natureza somente o que ela pode repor; que mostra um sentido de solidariedade generacional, ao preservar. $\mathrm{Na}$ prática a sociedade deve mostrar-se capaz de assumir novos hábitos e de projetar um tipo de desenvolvimento que cultive o cuidado com os equilíbrios ecológicos e funcione dentro dos limites impostos pela natureza. Não significa voltar ao passado, mas oferecer um novo enfoque para o futuro comum. Não se trata simplesmente de não consumir, mas de consumir responsavelmente ( BOFF, 2001, p.137).

Podemos observar que, tanto Leff como Boff, trabalham sob a mesma perspectiva voltada para a sustentabilidade do planeta. O primeiro pautado na racionalidade, enquanto que o outro dentro de uma expectativa de cuidado e amor. Independentemente da proposta, ambos visam a melhoria da qualidade da vida humana e do planeta Terra.

A educação, dentro desse contexto, assume papel importante enquanto formadora dessa 'racionalidade ambiental'. Do ponto de vista de Paulo Freire, através de uma educação libertadora e transformadora é possível pensar um futuro sustentável para as próximas gerações. " $A$ conscientização é uma das fundamentais tarefas de uma educação realmente libertadora". Libertadora de uma sociedade extremamente capitalista e opressora que afasta as pessoas de sua essência/natureza; e transformadora capaz de mudar a realidade para melhor vivermos (FREIRE, 1989, p.37).

Mas, para isso, os seres humanos precisam estar comprometidos com um mesmo propósito, alerta Freire. E "a primeira condição para que um ser possa assumir um ato comprometido está em ser capaz de agir e refletir sobre seu papel dentro da sociedade" (FREIRE, 1982, p.16).

Assim, é importante identificar como poderá ser tratado o tripé da sustentabilidade (ambiental, social, econômico) nas escolas, evidenciando os aspectos educativos ambientais com relação aos cuidados em relação ao planeta e proteção ambiental, através da promoção de vivências por meio do brincar e do contato com elementos da natureza no dia a dia das práticas pedagógicas.

O social, como direito da criança ao contato com o mundo natural, e a dignidade humana para a formação de uma postura ética diante dos cuidados com a natureza, através da Educação em Direitos Humanos, Art. $3^{\circ}$, "que visa promover a educação para a mudança e a transformação social, fundamentase nos seguintes princípios", inciso "I - dignidade humana e VII sustentabilidade socioambiental' (BRASIL, 2012).

Por fim, o econômico que terá seus reflexos sentidos na vida adulta da criança, quando esta for responsável pelas decisões da sociedade, cabendo a ela decidir sobre o que economicamente será viável preservar.

revista brasileira educação ambiental 


\section{Conclusões}

Desde a infância o ser humano passa por inúmeras fases até chegar à sua maturação. A infância, conforme discutido, é de vital importância pelo papel que exerce na formação do indivíduo, através da construção de valores, regras sociais de convívio, cuidados e afeto que lhe acompanharão por toda sua vida, tornando-a mais aberta para absorver ensinamentos.

Sendo assim, considerando que cada vez mais cedo as crianças passam a frequentar os espaços escolares e lá permanecem em espaços fechados por um período longo do dia, evidências apontam que essa situação tem colocado a criança em uma situação de distanciamento da natureza e da liberdade de brincar livremente em contato com os elementos naturais que tanto as atrai, como a água, terra, árvores, pedrinhas, areia, flores, sementes, dentre outros.

Percebeu-se com esse estudo que a falta de amor e cuidado com que a sociedade tem tratado o planeta Terra, pode estar diretamente relacionado ao distanciamento causado entre a criança e o seu contato com o mundo natural durante a fase infantil, ao afastá-la das vivências com o meio natural devido permanecerem emparedadas nas escolas.

Porém, já não é sem tempo de revermos os atos da relação que temos com nossa casa comum, o planeta Terra, se quisermos garantir que as próximas gerações possam desfrutar de toda a biodiversidade que o compõe.

Para tanto, de forma muito especial, a escola assume papel preponderante dentro desta concepção de sustentabilidade e cuidado com a natureza, possuindo a escola, em suas mãos, a base da formação do ser humano que será responsável pelo futuro do planeta.

Torna-se, portanto, imprescindível refletir sobre 0 tripé da sustentabilidade dentro do espaço escolar. A questão em pauta pode ser trabalhada dentro do contexto social, valorizando e reconhecendo seu aspecto social, quanto ao direito da criança à vivência com o mundo natural para a promoção dos cuidados que ela deve ter com a natureza. $O$ ambiental, o qual visa a formação e o conhecimento da biodiversidade que compõe esse imenso organismo vivo chamado Terra, suas possibilidades e limitações. E, por fim, o econômico que somente será sentido quando formarmos a futura geração. Essa nova geração, provavelmente, assumirá o valor contido nos cuidados com a natureza, e saberá agir diante do que seja economicamente viável preservar, entendendo que todos os recursos naturais são limitados, e que a humanidade e o próprio planeta Terra deles necessitam para viverem.

\section{Referências}

AHLERT, Alvori (Ed.). Ação comunicativa e ética no acesso e uso sustentável da água: a experiência do saneamento rural de Marechal Cândido Rondon PR. Horizonte, [s.I.], v. 11, n. 32, p.1571-1588, 16 dez. 2013. 
ALENCASTRO, M.S.. Hans Jonas e a proposta de uma ética para a civilização tecnológica. In: CUNHA, L.H.O.; FERREIRA, A.D.D. (Org.). Cultura, natureza e sustentabilidade: olhares distintos. 19. ed. Curitiba: UFPR, 2009. p. 13-27.

BRASIL. Constituição Federal, 1988. Brasília.

BRASIL. Lei no 8.069/90, 13 de julho de 1990. Estatuto da Criança e do Adolescente. Brasília.

BRASIL. Lei no 9394/1996, de 20 de dezembro de 1996. Lei de Diretrizes e Bases da Educação Nacional - LDB.

BRASIL. Lei o 13.257, de 09 de março de 2016. Dispõe Sobre as Políticas Públicas Para a Primeira Infância. Brasília.

BRASIL. Resolução no 05, de 17 de dezembro de 2009. Diretrizes Curriculares Nacionais para a Educação Infantil. Brasília.

BRASIL. Resolução № 1, de 30 de maio de 2012. Estabelece Diretrizes Nacionais para a Educação em Direitos Humanos. Diário Oficial da União, Brasília, 31 de maio de 2012 - Seção 1 - p. 48.

BRASIL. Lei no 9.795 , de 27 de abril de 1999. Dispõe sobre a educação ambiental, institui a Política Nacional de Educação Ambiental. Brasília.

BRASIL. Plano Nacional de Educação. Observatório PNE: Educação Infantil. 2015. Disponível em: <http://www.observatoriodopne.org.br/metas-pne/1educacao-infantil/indicadores>. Acesso em: 14 set. 2017.

BRASIL. Resolução no 2, de 15 de junho de 2012. Conselho Nacional de Educação: Estabelece as Diretrizes Curriculares Nacionais para a Educação Ambiental. Brasília.

BOFF, L. Ecologia: grito da terra, grito dos pobres. São Paulo: Ática S.A, 1995.

BOFF, L. Saber Cuidar: Ética do humano - compaixão pela terra. Rio de Janeiro: Editora Vozes, 7ª Ed., 2001.

BOFF, L. Sustentabilidade e educação. In: BOFF, L. Sustentabilidade: O que é - O que não é. Petrópolis: Vozes, 2012.

CARVALHO, I.C.M. Educação ambiental: a formação do sujeito ecológico. 6. ed. São Paulo: Cortez, 2012.

CARVALHO, V.D. et al. Interacionismo Simbólico: Origens, Pressupostos e Contribuições aos Estudos em Psicologia Social. Psicologia Ciência e Profissão, Df, v. 111, n. 3, p.146-161, jan. 2010.

DIAS, G.F. Educação ambiental: Princípios e práticas. 9. ed. São Paulo: Gaia Ltda, 2004. $551 \mathrm{p}$.

DIDONET, V. (Org.). Marco legal da primeira infância: A lei mais avançada do mundo para atender e zelar pelos direitos da criança pequena. 2018. Disponível em: <https://www.passeidireto.com/arquivo/56115201/introducaoao-marco-legal-da-prmeira-infancia-texto-para-dep-leandre>. Acesso em: 20 jun. 2018.

revista brasileira educação ambiental 
FLAVELL, J.H. A psicologia do Desenvolvimento de Jean Piaget. 5. ed. São Paulo: Biblioteca Pioneira de Ciência Sociais, 1996. 479 p.

FERRACIOLI, L. Aprendizagem, desenvolvimento e conhecimento na obra de Jean Piaget: uma análise do processo de ensino-aprendizagem em Ciências. Revista Brasileira de Estudos Pedagógicos, Brasília, v. 80, n. 194, p.5-18, abr. 1999.

FREIRE, P. Educação como prática da liberdade. 19. ed. Rio de Janeiro: Paz e Terra, 1989.

FREIRE, P. Educação e Mudança. 5. ed. Rio de Janeiro: Paz e Terra, 1982.

GADOTTI, Moacir. Pedagogia da Terra. 6. ed. São Paulo: Peirópolis, 2000. $217 \mathrm{p}$.

LEFF, E. Discursos Sustentáveis. São Paulo: Cortez, 2010. 293 p.

LEFF, E. Saber Ambiental: sustentabilidade, racionalidade, complexidade, poder. 11. ed. Rio de Janeiro: Vozes, 2015.

LOUREIRO, C.F.B. Sustentabilidade e Educação: um olhar da ecologia política. São Paulo: Cortez, 2012.

MOLON, S.I. As contribuições de Vygotsky na formação de educadores ambientais. In: LOUREIRO, C.F.B.; LAYRARGUES, P.P.; CASTRO, R.S. (Org.). Repensar a Educação Ambiental: um olhar crítico. São Paulo: Cortez, 2009. p. 141-172.

PADILHA, P.R. et al. Educação para a cidadania planetária: Currículo intertransdiciplinar em Osasco. São Paulo: Livraria Instituto Paulo Freire, 2011.

PEREIRA, C.M.M.C. et al. Ecopedagogia: uma nova pedagogia com propostas educacionais para o desenvolvimento sustentável. Educação Temática Digital, Campinas, v. 2, n. 8, p.80-89, jun. 2007.

REVISTA NOVA ESCOLA. Grandes Pensadores. edição 197 - nov/2006. São Paulo, Fundação Victor Civita - Editora Abril.

RÖHRS, H. Maria Montessori. Recife: Editora Massangana, 2010.

SANTOS, A.N.A. Ludicidade e infância: A importância do lúdico no aprendizado da criança. 2011. 72 f. TCC (Graduação) - Curso de Pedagogia, Centro de Educação, Comunicação e Artes Curso de Pedagogia, Universidade Estadual de Londrina - Uem, Londrina, 2011. Disponível em: $<$ http://www.uel.br/ceca/pedagogia/pages/arquivos/ALINNE NUNES ALVES DOS SANTOS.pdf>. Acesso em: 12 set. 2017.

SEBER, M.G. Construção da inteligência pela criança: atividades do período pré-operatório. São Paulo: Editora Scipione, 1989. 
TIRIBA, L. Crianças, natureza e educação infantil. 2005. 249 f. Tese (Doutorado) - Curso de Educação, Departamento de Educação do Centro de Teologia e Ciências Humanas da Puc-rio, Pontifícia Universidade Católica do Rio de Janeiro - Puc, Rio de Janeiro, 2005. Cap. 1. Disponível em: <http://www.nima.puc-rio.br/cursos/pdf/023 lea.pdf>. Acesso em: 13 set. 2017.

TIRIBA, L. Diálogo entre pedagogia e arquitetura. Presença Pedagógica. Belo Horizonte, Dimensão, v 14, n. 83, set./out.2008.

TIRIBA, L. et al. (Org.). O convívio com a natureza é um direito das crianças?: Reflexão sobre educação, escola e divórcio entre seres humano e natureza. In: SILVA, A.M.M. et al. (Org.). Direito ao meio ambiente como direito à vida: desafios para a educação em direitos humanos. São Paulo: Cortez, 2004. Cap. 2. p. 113-137.

VYGOTSKY, L.S. A formação social da mente. 4. ed. São Paulo: Livraria Martins Fontes Editora Ltda, 1991. 